\title{
Ultra-wide-field fundus imaging of acute retinal necrosis: clinical characteristics and visual significance
}

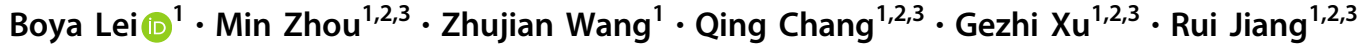

Received: 16 December 2018 / Accepted: 2 September 2019 / Published online: 25 September 2019

(c) The Author(s), under exclusive licence to The Royal College of Ophthalmologists 2019

\begin{abstract}
Objectives To investigate the clinical characteristics of acute retinal necrosis (ARN) with ultra-wide-field imaging (UWFI) and analyse their visual significance.

Methods Clinical and UWFI records of patients diagnosed with ARN at a single centre over 2 years were reviewed.

Results In 38 eyes of 35 patients, the clinical manifestations of ARN on UWFI included patchy (12 eyes) or fan-shaped necrotic lesions (26 eyes), retinal arterial obliteration (38 eyes), vitritis (38 eyes), retinal venous haemorrhage (19 eyes), and vitreous haemorrhage (6 eyes). Retinal detachment was associated with the number of retinal quadrants involved $(\beta=2.145$, $P=0.005)$. LogMAR BCVA at last follow-up was associated with $\log$ MAR BCVA at presentation $(\beta=0.473, P=0.004)$ and retinal detachment $(\beta=0.367, P=0.020)$.

Conclusion UWFI is useful for detecting retinal lesions in ARN, especially peripheral lesions or through opaque media, and provides valuable information concerning visual prognosis.
\end{abstract}

\section{Introduction}

Acute retinal necrosis (ARN) is an infectious retinitis caused by members of the herpes virus family [1], and was first described by Urayama in 1971 [2]. It is characterized by acute panuveitis with retinal periarteritis, progressing to diffuse necrotizing retinitis and retinal detachment (RD) [3]. It is defined by the American Uveitis Society according to its clinical characteristics and

These authors contributed equally: Boya Lei, Min Zhou

Supplementary information The online version of this article (https:// doi.org/10.1038/s41433-019-0587-8) contains supplementary material, which is available to authorized users.

Rui Jiang

2jiang@163.com

1 Department of Ophthalmology, Eye and ENT Hospital of Fudan University, Shanghai, China

2 Shanghai Key Laboratory of Visual Impairment and Restoration, Fudan University, Shanghai, China

3 NHC Key Laboratory of Myopia (Fudan University), Laboratory of Myopia, Chinese Academy of Medical Sciences,

Shanghai, China disease course [4]. Because of the peripheral circumferential spread of the disease, clinical documentation is difficult with routine fundus cameras, which have a limited field capacity of $30^{\circ}$ or $50^{\circ}$ [5]. Peripheral imaging performed with seven standard fields, according to the Airlie House classification of the Early Treatment of Diabetic Retinopathy Study, captures a field of up to $75^{\circ}$ [6], but this technique relies on the expertise of the operator, dilatation of the pupil, and patient cooperation.

The new ultra-wide-field (UWF) scanning laser ophthalmoscopic (SLO) imaging device can capture $200^{\circ}$ of the retina in a single image, even through an undilated pupil [7]. Previous studies have reported that these high-resolution images allow the clear documentation of peripheral retinal lesions, and has been used in several previous studies to document disease severity in posterior uveitis or panuveitis [8-11]. Although the analysis of ARN with UWF imaging has been reported [12, 13], these have been single case reports or small case series. The clinical characteristics and visual significance of UWF imaging in ARN patients have not been described in detail in a substantial series.

In this study, we used UWF imaging to investigate the clinical characteristics of 38 eyes of 35 ARN patients and analysed their visual significance. 


\section{Methods}

\section{Inclusion criteria and data collection}

In this retrospective observational case series, UWF pseudocolour SLO images were collected from ARN patients at their first presentation, over a 2-year period (from April 2016 to March 2018) at a single centre (Department of Ophthalmology, Eye and ENT Hospital of Fudan University, Shanghai, China).

All the eyes included met the AUS diagnostic criteria for ARN. We reviewed the demographic and clinical data at presentation and the last follow-up, including age, sex, aqueous tap (conducted for a diagnostic polymerase chain reaction $[\mathrm{PCR}] \mathrm{DNA}$ analysis), occurrence of $\mathrm{RD}$, the period between the onset of symptoms and the appropriate treatment, type of treatment, and best corrected visual acuity (BCVA; in Snellen visual acuity ratios, and in logarithms of the minimum angle of resolution [logMAR] when used for the purpose of statistical analysis. Nonnumerical vision was assigned $\log$ MAR scores of 2.0 for counting fingers [CF], 3.0 for hand motion [HM], light perception [LP], and no light perception [NLP].) This study complied with the tenets of the Declaration of Helsinki and was approved by the Institutional Review Board of the Eye and ENT Hospital of Fudan University, Shanghai, China. All the patients provided their informed consent to their participation in this clinical study before the study commenced.

\section{Acquisition and analysis of UWF images}

All UWF images were acquired with a UWF SLO retinal imaging system (Optos 200Tx, Optos PLC, Dunfermline, UK) within $24 \mathrm{~h}$ of the first presentation and before treatment began. The Optos 200Tx uses red $(633 \mathrm{~nm})$ and green $(532 \mathrm{~nm})$ lasers to generate colour images, which are reflected off a large concave ellipsoidal mirror. The resulting images are displayed as red only, green only, or as a combination of red and green false-colour images. The combination of red and green false-colour images was analysed in the present series. The UWF images were evaluated independently by two experienced investigators (Rui Jiang and Min Zhou), and a consensus was reached in each case.

\section{Photographic grading of media clarity}

Media clarity assessment was based on the UWF images, referring to the methods reported before [14] with some modifications. The media were classified as either: (1) inability to see a retinal vessel; (2) inability to see a secondorder retinal vessel, but with some retinal vessels visible; (3) a second-order retinal vessel visible, but the outline of the vessel unclear; or (4) second-order retinal vessels visible and clearly discernible. The assessment of media clarity is illustrated in the supplementary file. To meet the necessary statistical preconditions, the media classified as category 3 or 4 were redefined as 'slight vitreous opacity' and the media classified as category 1 or 2 were redefined as 'severe vitreous opacity'.

\section{Assessment of the necrotic retinal lesions included the morphology and the zones and quadrants involved}

The involved eyes were classified into two categories according to the different morphological characteristics of the necrotic retinal lesions determined in the UWF images: eyes with patchy lesions and eyes with fan-shaped lesions. The patchy lesions were dispersed, either round or oval necrotic lesions; the fan-shaped lesions were larger lesions, usually with a fan-shaped outline with the tip directed toward the posterior pole. The different morphological characteristics of the necrotic retinal lesions are illustrated in Fig. 1a, b.

The UWF images were divided into three zones, combining the previous defined zones for CMV retinitis [15] and peripheral zones for age-related macular degeneration [16]. Zone 1 incorporates a circular area of a two-disc diameter radius cantered on the fovea merged with another circle of one-disc diameter from the optic disc margin. Zone 2 at the mid periphery included the areas outside zone 1 and within a concentric ring of $11,000 \mu \mathrm{m}$ in radius from the foveola [16]. The concentric rings defining the zones were based on the distance between the centres of the optic nerve head and the foveola (deemed to be $4500 \mu \mathrm{m}$ ) [16]. Zone 3 at the far periphery essentially included all the areas outside zone 2. The eyes were classified into three categories according to the different zones involved: (1) only zone 3 at the far periphery was involved; (2) both zone 2 and zone 3 were involved; or (3) all zones were involved. To meet the necessary statistical precondition, retinal involvement of only zone 3 was defined as 'anterior involvement', and retinal involvement of zone 2 and/or 1 was defined as 'posterior involvement'.

The UWF images were subdivided into four quadrants through the centre of the fovea: the temporal and nasal superior quadrants and the temporal and nasal inferior quadrants. The eyes were classified into four categories according to numbers of quadrants involved.

The classifications of the zones and quadrants involved are illustrated in Fig. 1c.

\section{Assessment of retinal vessels}

Obliteration of the retinal arteries and haemorrhage along the retinal veins were observed in the involved eyes. For 
Fig. 1 Representative UWF images showing the clinical characteristics of ARN. a Patchy necrotic lesions; b fan-shaped necrotic lesions; $\mathbf{c}$ illustration of the classification of the involved retinal zones and quadrants; d illustration of arterial obliteration (arrows), haemorrhage along the retinal veins (arrowheads), and vitreous haemorrhage (asterisk). ARN acute retinal necrosis, UWF ultra-wide-field
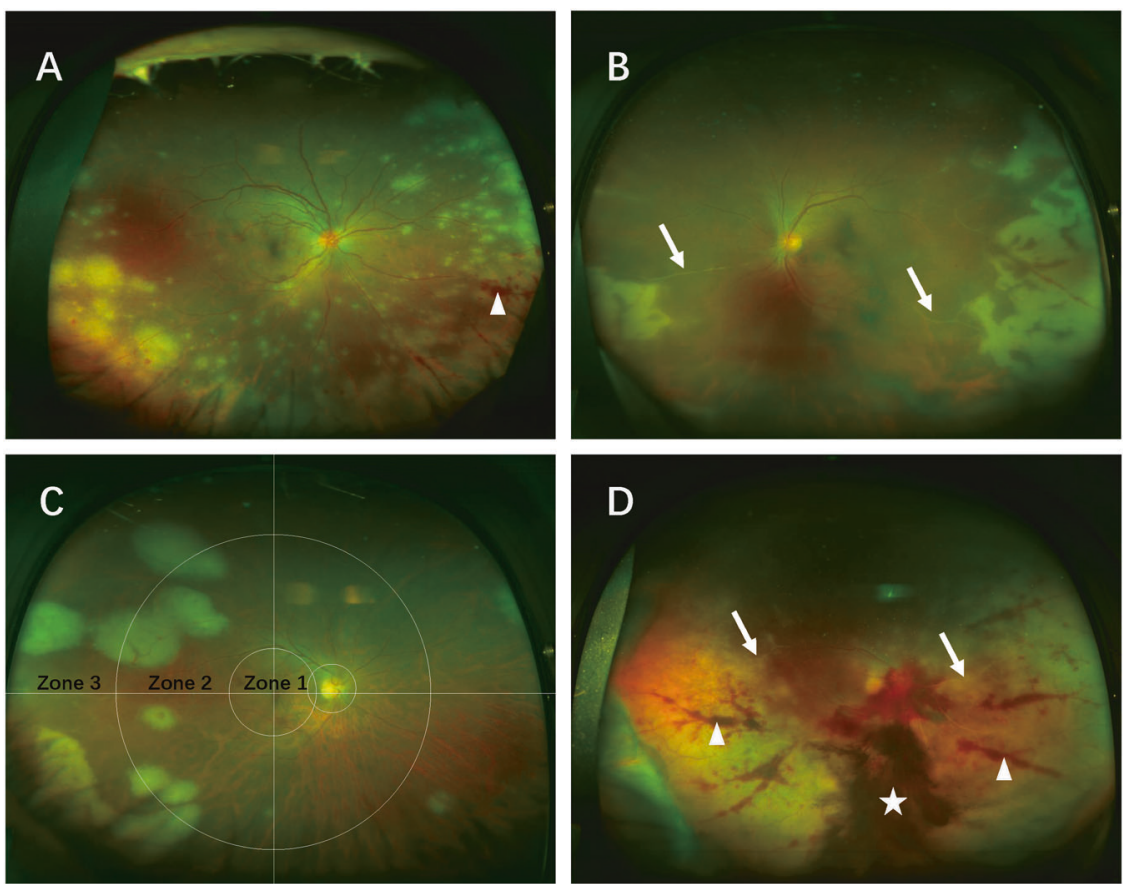

Table 1 Baseline characteristics of the study subjects
Sex

Age

Period between the onset of eye symptoms and diagnosis

PCR results $(n, \%)$

Duration of follow-up
21 males $(60.0 \%) ; 14$ females $(40.0 \%)$

$51.0 \pm 11.3$ years (range, $16-71$ )

$14.6 \pm 5.6$ days (range, $3-21$ )

$\operatorname{VZV~(33/34,~97.1\% ),~HSV-2~(1/34,~2.9\% )~}$

$10.8 \pm 5.7$ months (range, $3-22$ )

$H S V$ herpes simplex virus, $P C R$ polymerase chain reaction, $V Z V$ varicella zoster virus

eyes with obvious vitreous opacity, the retinal vessels were assessed 1 week after normative systemic and local antiviral therapies had begun. In addition to the obliteration of the retinal arteries and haemorrhage along the retinal veins, vitreous haemorrhage was observed in some eyes. The assessment of the retinal vessels is shown in Fig. 1d.

\section{Statistical analysis}

The clinical and imaging data are presented as numerical, categorical, or ordinal data. The normality of the numerical data was examined with histograms. Their distributions were positively skewed, so we used nonparametric tests, including the Wilcoxon test, Mann-Whitney $U$ test, Spearman correlation coefficient $(r)$, and $\chi^{2}$ test to assess their relationships. A multiple regression analysis and a multiple logistic regression analysis were used to identify the UWF imaging parameters that remained independently associated with the visual function parameters. Values of $P<0.05$ were considered statistically significant. The statistical analyses were performed with SPSS for Windows version 17.0 (SPSS Inc., Chicago, IL, USA).

\section{Results}

\section{Baseline characteristics}

In total, 38 eyes of 35 patients (21 men and 14 women) were evaluated in this study. The patients' demographic data are listed in Table 1. Seven patients suffered from bilateral ARN, and seven of the 38 eyes were secondaffected eyes of the same patient. Wide-field images were not taken in the initially affected eyes for four patients with bilateral ARN, these four eyes were excluded from the study. All patients were immunocompetent, without any primary (congenital) or secondary immune deficiencies [17]. Of these 38 eyes, 34 underwent aqueous humour biopsies for diagnostic PCR.

\section{Clinical characteristics based on UWF images}

With the UWF imaging technique, the characteristics of ARN can be detected comprehensively in a single image. Retinal necrotic lesions, retinal arterial obliteration, and inflammatory vitreous opacity were detected in $38 / 38$ 
(100\%) eyes. Haemorrhage along the retinal veins was observed in 19/38 (50.0\%) eyes. Vitreous haemorrhage was observed in $6 / 38(15.8 \%)$ eyes.

In the total 38 eyes, vitreous opacity classified as category 1 was detected in 6 eyes, category 2 in 9 eyes, category 3 in 17 eyes, and category 4 in 6 eyes. Patchy retinal lesions were observed in 12 eyes and fan-shaped retinal lesions were observed in 26 eyes. Only the far periphery was involved in 14 eyes; the far periphery and mid periphery were both involved in 14 eyes; and the posterior pole was involved in 10 eyes. Only one quadrant was involved in 4 eyes; two quadrants were involved in 5 eyes; three quadrants were involved in 4 eyes; and all four quadrants were involved in the remaining 25 eyes. Necrotic lesions and retinal arterial obliteration were present in the same quadrants.

\section{Treatment and outcomes}

All patients received intravenous antiviral treatment (ganciclovir, $5 \mathrm{mg} / \mathrm{kg} \mathrm{q} 12 \mathrm{~h}$ ) for 2 weeks, followed by oral antiviral treatment (valaciclovir, $600 \mathrm{mg}$ three times a day) for a further 6-8 weeks. Intravitreal antiviral injections (ganciclovir, $4 \mathrm{mg} / 0.1 \mathrm{ml}$ twice a week) were administered immediately after ARN was suspected until the absence of active areas of retinitis was observed by the experienced investigators (Rui Jiang and Min Zhou), and could be administered for up to 4 weeks ( 9 injections in total). Nine eyes suffered from mild ocular lesions; an average of $5.2 \pm$ 2.1 injections (range, 2-8 injections) was performed in these eyes. Six eyes suffered from severe ocular involvement with $\mathrm{RD}$ and received vitrectomy in the first 4 weeks after presentation. Peripheral necrotic retina was removed with vitrectomy, and intravitreal antiviral injections were discontinued after vitrectomy. An average of $4.7 \pm 1.8$ injections (range, 1-6 injections) were performed in these eyes. The remaining 23 eyes received all nine intravitreal antiviral injections lasting for 4 weeks. An intravitreal injection of corticosteroid (triamcinolone acetonide, $2 \mathrm{mg} / 0.1 \mathrm{ml}$ ) was given at the time of the second antiviral injection (3-4 days after the commencement of antiviral therapy) in eyes with significant intraocular inflammation. When RD was observed, a therapeutic vitrectomy was performed, with silicon oil as the intraocular tamponade.

The mean $\log$ MAR BCVA was $1.2 \pm 1.1$ (range, NLP to $20 / 25$, Snellen equivalent 20/333) at presentation, and $0.9 \pm$ 0.9 (range, NLP to 20/20, Snellen equivalent 20/160) at the last follow-up ( $P=0.063$ on the Wilcoxon test) (Fig. 2). Visual acuity improved in 26 eyes (68.4\%), stayed the same in 2 eyes (5.3\%), and worsened in 10 eyes $(26.3 \%)$. The final visual acuity was better than or equal to $0.5 \log$ MAR in 15 eyes $(39.5 \%)$. Twenty-two $(57.9 \%)$ of the 38 eyes suffered $\mathrm{RD}$, four eyes at presentation, and 18 eyes during follow-up. The mean period between the occurrence of RD and presentation was $5.9 \pm 8.4$ weeks (range, 0-34). Attached retinas were observed at the last follow-up in all the eyes treated with vitrectomy.

\section{Visual significance of UWF imaging parameters}

The relationships between the parameters of visual functions and the characteristics on the UWF images are listed in Table 2.

The $\log$ MAR BCVA at presentation was evaluated in a stepwise multivariable regression model (including whether the eye was the second involved eye, the extent of vitreous opacity, the number of quadrants involved, and the presence of posterior involvement). The variable that remained independently associated with $\operatorname{logMAR} \mathrm{BCVA}$ at presentation was posterior involvement $(\beta=0.516, P=0.002)$.

The occurrence of RD was evaluated with a logistic multivariable regression model (including whether the eye was the second involved eye, the extent of vitreous opacity, number of quadrants involved, the presence of posterior involvement, and the occurrence of vitreous haemorrhage). The variable that remained independently associated with the occurrence of RD was the number of quadrants involved $(\beta=2.145, P=0.005)$.

LogMAR BCVA at the last follow-up was evaluated in a stepwise multivariable regression model (including whether the eye was the second involved eye, the number of quadrants involved, the presence of posterior involvement, logMAR BCVA at presentation, and the occurrence of RD). The variables that remained independently associated with $\log$ MAR BCVA at the last follow-up were $\log$ MAR BCVA at presentation $(\beta=0.473, P=0.004)$ and the occurrence of RD $(\beta=0.367, P=0.020)$.

\section{Discussion}

In this study, we used UWF SLO imaging to retrospectively analyse 38 eyes of 35 patients suffering ARN, to report the clinical characteristics and visual outcomes of ARN. To the best of our knowledge, this case series includes the largest number of ARN patients treated with a UWF imaging technique.

ARN is an ophthalmic emergency with rapid disease progression, delays in diagnosis, and treatment often lead to poor prognoses [18]. ARN is always associated with significant changes in the peripheral retina in early stages of the disease and obvious vitreous opacity in late stages of the disease [19], which make it difficult to diagnose accurately and therefore challenging to select an appropriate treatment. In the present series, the necrotic lesions were located exclusively in the far periphery in 14 eyes $(36.8 \%)$, and 
were therefore difficult to document with routine fundus cameras. They may have been missed during a fundus slitlamp examination that was performed with insufficient care. Severe vitreous opacity was observed in 15 eyes (39.5\%), with only some retinal vessels visible but no second-order retinal vessels visible, or even with no retinal vessels visible. UWF imaging has been reported to be useful in the management of uveitis, including tubercular posterior uveitis [11], Behçet retinal vasculitis [9], tubulointerstitial nephritis and uveitis syndrome [20], and others [10]. However, reports of its use in ARN are limited in the literature. UWF imaging allows the clear documentation of peripheral retinal lesions because it captures a $200^{\circ}$ view in a single image $[9,16]$, which facilitates the early diagnosis

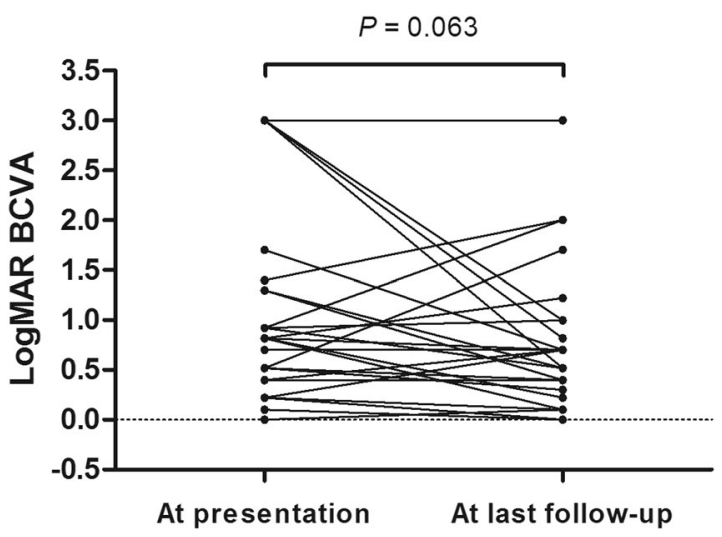

Fig. 2 LogMAR BCVA at presentation and at last follow-up of the involved eyes treated with normative antiviral therapy. BCVA best corrected visual acuity, logMAR logarithm of the minimum angle of resolution of ARN. The strong penetration of the red laser allows UWF imaging to penetrate media opacities [9,21]. Even in patients with significant vitritis, we were able to identify the necrotic retinal lesions to make a correct diagnosis and inform our therapeutic decisions. All these advances make UWF imaging a powerful auxiliary tool for early diagnosis and treatment of ARN.

UWF images enable the morphological characteristics of the necrotic retinal lesions to be observed more comprehensively in a single image than is possible with other technologies. Two categories were identified: patchy lesions and fan-shaped lesions. Both kinds of necrotic lesions can present as separated or confluent, based on the clinical stage of the disease $[22,23]$. It is unclear why retinal lesions display these two different morphological characteristics. Differences in the host's immune status is a possible explanation. The clinical characteristics and immunological profiles of patients with ARN were investigated and discussed in Rochat's and Guex-Crosier's series [24, 25] using sensitive methods, including the delayed-type hypersensitivity skin test, in vitro lymphocytic activation test, and a blood lymphocyte subpopulation analysis. It was suggested that the spectrum of clinical forms reflects the different clinical characteristics of ARN. Patients with normal immunity tend to develop typical ARN, with larger lesions and pronounced vitritis, whereas at the other end of the spectrum, the disease is more severe in patients with severely impaired immunity, resembling progressive outer retinal necrosis, with posterior pole involvement, extensive retinal involvement, and a poor visual prognosis. This is consistent with our observations in this series (Table 3). In

Table 2 Relationship between parameters of visual functions and characteristics of UWF images

\begin{tabular}{|c|c|c|c|c|c|c|c|}
\hline & & \multicolumn{2}{|c|}{$\begin{array}{l}\text { LogMAR BCVA } \\
\text { at presentation }\end{array}$} & \multicolumn{2}{|c|}{$\begin{array}{l}\text { Occurrence of } \\
\text { retinal } \\
\text { detachment }\end{array}$} & \multicolumn{2}{|c|}{$\begin{array}{l}\text { LogMAR BCVA } \\
\text { at the last follow- } \\
\text { up }\end{array}$} \\
\hline & & $r$ & $P$ value & $r$ & $P$ value & $r$ & $P$ value \\
\hline \multirow[t]{4}{*}{ Clinical characteristic } & Sex & -0.041 & 0.818 & - & $0.309^{\mathrm{a}}$ & 0.175 & 0.322 \\
\hline & Age & 0.213 & 0.226 & 0.193 & 0.245 & 0.072 & 0.685 \\
\hline & $\begin{array}{l}\text { Period between the onset of eye symptoms and } \\
\text { diagnosis }\end{array}$ & 0.162 & 0.359 & 0.060 & 0.737 & 0.084 & 0.660 \\
\hline & Second eye involvement & -0.444 & 0.009 & - & $0.028^{\mathrm{a}}$ & -0.400 & 0.019 \\
\hline \multirow{5}{*}{$\begin{array}{l}\text { Characteristic of UWF retinal } \\
\text { imaging }\end{array}$} & Severity of vitreous opacity & 0.435 & 0.010 & 0.471 & 0.003 & 0.191 & 0.280 \\
\hline & Number of quadrants involved & 0.387 & 0.024 & 0.660 & $<0.001$ & 0.431 & 0.011 \\
\hline & Occurrence of posterior involvement & 0.516 & 0.002 & 0.454 & 0.004 & 0.477 & 0.004 \\
\hline & Morphological characteristics of the necrotic lesions & -0.142 & 0.442 & - & $0.504^{\mathrm{a}}$ & -0.067 & 0.708 \\
\hline & Occurrence of vitreous haemorrhage & 0.273 & 0.118 & - & $0.030^{\mathrm{a}}$ & 0.210 & 0.234 \\
\hline \multirow[t]{2}{*}{ Others } & LogMAR BCVA at presentation & - & & - & & 0.599 & $<0.001$ \\
\hline & Occurrence of retinal detachment & - & & - & & 0.545 & 0.001 \\
\hline
\end{tabular}

$B C V A$ best corrected visual acuity, $\log M A R$ logarithm of the minimum angle of resolution, $U W F$ ultra-wide-field ${ }^{\mathrm{a}} \chi^{2}$ test (Fisher exact test) 
Table 3 Comparison of eyes with patchy or fan-shaped necrotic retinal lesions

\begin{tabular}{|c|c|c|c|c|c|}
\hline & & & Patchy lesions & $\begin{array}{l}\text { Fan-shaped } \\
\text { lesions }\end{array}$ & $P$ value \\
\hline \multirow[t]{4}{*}{ Clinical characteristic } & \multicolumn{2}{|l|}{ Sex } & $5 \mathrm{M} / 7 \mathrm{~F}$ & $19 \mathrm{M} / 7 \mathrm{~F}$ & - \\
\hline & \multicolumn{2}{|l|}{ Age (years) } & $52.9 \pm 9.4$ & $51.0 \pm 11.9$ & 0.627 \\
\hline & \multicolumn{2}{|c|}{$\begin{array}{l}\text { Period between the onset of eye } \\
\text { symptoms and diagnosis (days) }\end{array}$} & $14.8 \pm 5.3$ & $14.5 \pm 5.8$ & 0.929 \\
\hline & \multicolumn{2}{|c|}{$\begin{array}{l}\text { Incidence of second eye involvement } \\
(n, \%)\end{array}$} & $1 / 12(8.3 \%)$ & $6 / 26(23.1 \%)$ & $0.395^{\mathrm{a}}$ \\
\hline \multirow[t]{6}{*}{$\begin{array}{l}\text { Characteristic of UWF retinal } \\
\text { imaging }\end{array}$} & \multicolumn{2}{|c|}{$\begin{array}{l}\text { Incidence of severe vitreous opacity } \\
(n, \%)\end{array}$} & $5 / 12(41.7 \%)$ & $10 / 26(38.5 \%)$ & $1.000^{\mathrm{a}}$ \\
\hline & \multirow{4}{*}{$\begin{array}{l}\text { Number of quadrants } \\
\text { involved }(n, \%)\end{array}$} & 1 & $0 / 12(0 \%)$ & $4 / 26(15.4 \%)$ & $0.287^{\mathrm{a}}$ \\
\hline & & 2 & $1 / 12(8.3 \%)$ & $4 / 26(15.4 \%)$ & $1.000^{\mathrm{a}}$ \\
\hline & & 3 & $1 / 12(8.3 \%)$ & $3 / 26(11.5 \%)$ & $1.000^{\mathrm{a}}$ \\
\hline & & 4 & $10 / 12(83.3 \%)$ & $15 / 26(57.7 \%)$ & $0.158^{\mathrm{a}}$ \\
\hline & \multicolumn{2}{|c|}{$\begin{array}{l}\text { Occurrence of posterior involvement } \\
(n, \%)\end{array}$} & $11 / 12(91.7 \%)$ & $13 / 26(50.0 \%)$ & $0.027^{\mathrm{a}}$ \\
\hline \multirow[t]{4}{*}{ Visual function } & \multicolumn{2}{|c|}{ LogMAR BCVA at presentation } & $1.5 \pm 1.2$ & $1.0 \pm 0.9$ & 0.205 \\
\hline & \multicolumn{2}{|c|}{$\begin{array}{l}\text { Occurrence of retinal detachment } \\
(n, \%)\end{array}$} & $8 / 12(66.7 \%)$ & $14 / 26(53.8 \%)$ & $0.504^{\mathrm{a}}$ \\
\hline & \multicolumn{2}{|c|}{ LogMAR BCVA at the last follow-up } & $1.0 \pm 0.9$ & $0.8 \pm 0.8$ & 0.669 \\
\hline & \multicolumn{2}{|c|}{ Duration of follow-up (months) } & $8.2 \pm 4.3$ & $11.8 \pm 5.9$ & 0.088 \\
\hline
\end{tabular}

$B C V A$ best corrected visual acuity, $F$ female, $\log M A R$ logarithm of the minimum angle of resolution, $M$ male, $U W F$ ultra-wide-field ${ }^{\mathrm{a}} \chi^{2}$ test (Fisher exact test)

the present study, the patchy lesions were more likely to be disseminated, with all four quadrants involvement and posterior involvement.

LogMAR BCVA at presentation and the last follow-up were worse and the occurrence of $\mathrm{RD}$ was higher in eyes with patchy lesions. Because the sample size was small, none of the differences was significant, except the differences in posterior involvement. Second eye involvement is thought to correlate with less-severe disease and a better visual outcome, partly because a stronger immune reaction is induced [26]. The proportion of second eye involvement was higher in eyes with fan-shaped lesions, suggesting that the average immune status of these patients was better than that of patients with patchy lesions. Although all patients included in the present series were thought to be immunocompetent because they suffered no primary or secondary immune deficiencies [17], some patients may have suffered an underlying immune dysfunction, which could not be investigated because the study was retrospective. A further well-designed study is still required to explain these differences.

The comprehensively presented characteristics of ARN in a single image with the UWF imaging technique allows the full extent of the disease involvement to be determined, and makes it easier for doctors to assess the severity of the disease and infer the possible visual prognosis. One independent risk factor that contributed to a poor visual outcome was the $\log$ MAR BCVA at presentation, which was independently associated with retinal zone involvement. This is consistent with the findings of previously published studies [27]. The other independent risk factor that contributed to a poor visual outcome was the development of RD, which was independently associated with the number of quadrants involved. This was also consistent with previously published studies [27]. It is believed that ARN is a rapidly progressive disease and the zones and quadrants involved are likely to change on a day to day basis. Interestingly, the period between the onset of eye symptoms and diagnosis was not associated with $\log \mathrm{MAR}$ BCVA at presentation, LogMAR BCVA at the last follow-up or occurrence of RD in the statistical analysis. The differences of speed and extent of disease progression in patients with different immune status might be an explanation.

In the present series, all eyes that developed RD showed 3-4 quadrants involvement, and the period between the occurrence of $\mathrm{RD}$ and presentation was $5.9 \pm 8.4$ weeks (range, 0-34), which indicated that eyes with retinal involvement in more than two quadrants should be followed up closely, even after the cessation of antiviral therapy. Because the incidence of RD is high in ARN, some ophthalmologists have advocated prophylactic laser photocoagulation to lessen this risk [27-30]. However, others have contested this view $[18,19]$. The prevalence of RD $(57.9 \%)$ in the present series was similar to that in other published studies $[28,31]$. 
Prophylactic laser photocoagulation was not performed in the present study, mainly because it is difficult to determine the correct time to perform it. Prophylactic laser photocoagulation has failed to prevent RD in the early stages of the disease, for the involved retinal area continued to extend posteriorly, beyond the demarcation of the laser burns [19]. UWF imaging can show the extent of disease involvement in a single image, which is extremely valuable in monitoring the progression and healing response of the necrotic lesions at each visit. Therefore, UWF imaging may allow doctors to decide when to conduct prophylactic laser photocoagulation after sequential observations and analyses, and this warrants further investigation.

As for the choice of antiviral drugs, no single treatment strategy had been established as the standard therapy for ARN. Acyclovir was used widely for therapy and prevention of VZV and HSV disease [32]. Ganciclovir, a homologue of acyclovir, exhibits enhanced activity against CMV, and similar activity against VZV and HSV[33-37]. Oral valaciclovir and valganciclovir, the prodrugs of acyclovir and ganciclovir, are also effective when intravenous treatment is not feasible $[38,39]$. In addition to systemic antiviral therapy, intravitreal antiviral injections (ganciclovir or foscarnet) have been used for adjunctive therapy of ARN [40-42]. Some authors prefer intravitreal foscarnet to guard against possible viral resistance [43, 44]. Although other treatment strategies are preferred by some centres, we choose a comprehensive antiviral therapy including intravenous ganciclovir, followed by oral valaciclovir, and intravitreal ganciclovir injections in the present study. The necrotic retinal lesions can be effectively controlled with this therapy. The standard therapy for ARN still needs further study and discussion.

Our study had a number of limitations. First, it was a retrospective study and the basic information was obtained from a review of medical records. Moreover, the sample of ARN patients was small, so some statistical analyses could not be performed. Therefore, larger numbers of patients are required in future studies. Furthermore, the analysis of the UWF images was rough, and a lot of detailed information was missed. Further interpretation of the UWF images with quantitative indices, such as the areas of the necrotic lesions, could provide more valuable information. Finally, the study was a cross-sectional analysis of UWF images, with no sequential observations. Further observations during follow-up will be of great value.

In summary, the ultra-wide view and strong penetration of media opacity possible with the UWF imaging technique allow the characteristics of ARN to be comprehensively determined in a single image. The $\log$ MAR BCVA at presentation was independently associated with posterior retinal involvement, and RD was independently associated with the number of quadrants involved. The logMAR
BCVA at the last follow-up was independently associated with the $\log$ MAR BCVA at presentation and the occurrence of RD. Further longitudinal studies are required, with larger samples, to evaluate the potential impact of this imaging modality on patient management and outcomes.

\section{Summary}

\section{What was known before}

- ARN is associated with significant changes in the peripheral retina and obvious vitreous opacity, which is hard to be documented with routine fundus cameras.

- UWF imaging has been reported to be useful in the management of uveitis with ultra-wide view and strong penetration of media opacity.

\section{What this study adds}

- The clinical characteristics and visual significance of ARN patients in a substantial series was investigated with UWF imaging.

- UWF imaging is found to be useful for detecting retinal lesions in ARN, especially peripheral lesions or through opaque media, and provides valuable information concerning visual prognosis.

Acknowledgements The authors thank Zhijian Jiang, Jianhong Dong (Department of Ophthalmology, Shanghai Xuhui Central Hospital, Shanghai, China) for their contributions to data collection; and Ruiping Gu (Department of Ophthalmology, Eye and ENT Hospital of Fudan University, Shanghai, China) for revising the paper.

Funding This work was supported by the National Natural Science Foundation of China under Grant 81570854 and 81770944; the Science and Technology Commission of Shanghai Municipality under Grant 16411953700 and 18411965100; the Shanghai Hospital Development Center under Grant SHDC12016116.

\section{Compliance with ethical standards}

Conflict of interest The authors declare that they have no conflict of interest.

Publisher's note Springer Nature remains neutral with regard to jurisdictional claims in published maps and institutional affiliations.

\section{References}

1. Chang S, Young LH. Acute retinal necrosis: an overview. Int Ophthalmol Clin. 2007;47:145-54.

2. Urayama A. Unilateral acute uveitis with retinal peri-arteritis and detachment. JpnJ Clin Ophthalmol. 1971;25:607e19. 
3. Schoenberger SD, Kim SJ, Thorne JE, Mruthyunjaya P, Yeh S, Bakri SJ, et al. Diagnosis and treatment of acute retinal necrosis: a report by the American Academy of Ophthalmology. Ophthalmology. 2017;124:382-92.

4. Holland GN. Standard diagnostic criteria for the acute retinal necrosis syndrome. Executive Committee of the American Uveitis Society. Am J Ophthalmol. 1994;117:663-7.

5. Witmer MT, Kiss S. Wide-field imaging of the retina. Surv Ophthalmol. 2013;58:143-54.

6. The Diabetic Retinopathy Study Research Group. Report number 6 design, methods, and baseline results. A modification of the Airlie House classification of diabetic retinopathy. Prepared by the diabetic retinopathy. Investig Ophthalmol Vis Sci. 1981;21: $1-226$.

7. Manivannan A, Plskova J, Farrow A, Mckay S, Sharp PF, Forrester JV. Ultra-wide-field fluorescein angiography of the ocular fundus. Am J Ophthalmol. 2005;140:525-7.

8. Kaines A, Tsui I, Sarraf D, Schwartz S. The use of ultra wide field fluorescein angiography in evaluation and management of uveitis. Semin Ophthalmol. 2009;24:19-24.

9. Mesquida M, Llorenç V, Fontenla JR, Navarro MJ, Adán A. Use of ultra-wide-field retinal imaging in the management of active Behçet retinal vasculitis. Retina. 2014;34:2121-7.

10. Campbell JP, Leder HA, Sepah YJ, Gan T, Dunn JP, Hatef E, et al. Wide-field retinal imaging in the management of noninfectious posterior uveitis. Am J Ophthalmol. 2012;154: 908-11.

11. Aggarwal K, Mulkutkar S, Mahajan S, Singh R, Sharma A, Bansal R, et al. Role of ultra-wide field imaging in the management of tubercular posterior uveitis. Ocul Immunol Inflamm. 2016;24:631-6.

12. Tripathy K, Sharma YR, Gogia V, Venkatesh P, Singh SK, Vohra R. Serial ultra wide field imaging for following up acute retinal necrosis cases. Oman J Ophthalmol. 2015;8:71-72.

13. Neubauer AS, Yu A, Haritoglou C, Ulbig MW. Peripheral retinal changes in acute retinal necrosis imaged by ultra widefield scanning laser ophthalmoscopy. Acta Ophthalmol Scand. 2005;83:758-60.

14. Endophthalmitis Vitrectomy Study Group. Results of the endophthalmitis vitrectomy study. A randomized trial of immediate vitrectomy and of intravenous antibiotics for the treatment of postoperative bacterial endophthalmitis. Arch Ophthalmol. 1995;113:1479-96.

15. Holland GN, Buhles WC Jr, Mastre B, Kaplan HJ, UCLA CMV Retinopathy Study Group. A controlled retrospective study of ganciclovir treatment for cytomegalovirus retinopathy. Use of a standardized system for the assessment of disease outcome. Arch Ophthalmol. 1989;107:1759-66.

16. Lengyel I, Csutak A, Florea D, Leung I, Bird AC, Jonasson F, et al. A population-based ultra-widefield digital image grading study for age-related macular degeneration-like lesions at the peripheral retina. Ophthalmology. 2015;122:1340-7.

17. Rubin LG, Levin MJ, Ljungman P, Davies EG, Avery R, Tomblyn M, et al. 2013 IDSA clinical practice guideline for vaccination of the immunocompromised host. Clin Infect Dis. 2014;58: e44-100.

18. Tibbetts MD, Shah CP, Young LH, Duker JS, Maguire JI, Morley MG. Treatment of acute retinal necrosis. Ophthalmology. 2010;117:818-24.

19. Roy R, Pal BP, Mathur G, Rao C, Das D, Biswas J. Acute retinal necrosis: clinical features, management and outcomes-a 10 year consecutive case series. Ocul Immunol Inflamm. 2014;22:170-4.

20. Yang M, Chi Y, Guo C, Huang J, Yang L, Yang L. Clinical profile, ultra-wide-field fluorescence angiography findings, and long-term prognosis of uveitis in tubulointerstitial nephritis and uveitis syndrome at one tertiary medical institute in China. Ocul Immunol Inflamm. 2017;30:1-9.
21. Kozak I, Arevalo JF. Atlas of wide-field retinal angiography and imaging. Basel: Springer International Publishing AG Switzerland; 2016.

22. Duker JS, Nielsen JC, Eagle RC Jr, Bosley TM, Granadier R, Benson WE. Rapidly progressive acute retinal necrosis secondary to herpes simplex virus, type 1. Ophthalmology. 1990;97: $1638-43$.

23. el Azazi M, Samuelsson A, Linde A, Forsgren M. Intrathecal antibody production against viruses of the herpesvirus family in acute retinal necrosis syndrome. Am J Ophthalmol. 1991;112:76-82.

24. Rochat C, Polla BS, Herbort CP. Immunological profiles in patients with acute retinal necrosis. Graefes Arch Clin Exp Ophthalmol. 1996;234:547-52.

25. Guex-Crosier Y, Rochat C, Herbort CP. Necrotizing herpetic retinopathies. A spectrum of herpes virus-induced diseases determined by the immune state of the host. Ocul Immunol Inflamm. 1997;5:259-65.

26. Okunuki Y, Usui Y, Kezuka T, Takeuchi M, Goto H. Four cases of bilateral acute retinal necrosis with a long interval after the initial onset. Br J Ophthalmol. 2011;95:1251-4.

27. Meghpara B, Sulkowski G, Kesen MR, Tessler HH, Goldstein DA. Long-term follow-up of acute retinal necrosis. Retina. 2010;30:795-800.

28. Lau CH, Missotten T, Salzmann J, Lightman SL. Acute retinal necrosis features, management, and outcomes. Ophthalmology. 2007;114:756-62.

29. Han DP, Lewis H, Williams GA, Mieler WF, Abrams GW, Aaberg TM. Laser photocoagulation in the acute retinal necrosis syndrome. Arch Ophthalmol. 1987;105:1051-4.

30. Sternberg P Jr, Han DP, Yeo JH, Barr CC, Lewis H, Williams GA, et al. Photocoagulation to prevent retinal detachment in acute retinal necrosis. Ophthalmology. 1988;95:1389-93.

31. Hillenkamp J, Nölle B, Bruns C, Rautenberg P, Fickenscher H, Roider J. Acute retinal necrosis: clinical features, early vitrectomy, and outcomes. Ophthalmology. 2009;116:1971-5.

32. Field HJ, Vere Hodge RA. Recent developments in antiherpesvirus drugs. Br Med Bull. 2013;106:213-49.

33. Crumpacker CS. Ganciclovir. N Engl J Med. 1996;335:721-9.

34. Field AK, Davies ME, DeWitt C, Perry HC, Liou R, Germershausen J, et al. 9-([2-hydroxy-1-(hydroxymethyl)ethoxy]methyl) guanine: a selective inhibitor of herpes group virus replication. Proc Natl Acad Sci USA. 1983;80:4139-43.

35. Xu HY, Li MD, Ye JJ, Zhao C, Hu YT, Di Y. Varicella-zoster virus as a causative agent of acute retinal necrosis in younger patients. Chin Med J . 2019;132:659-63.

36. Mori T, Shimizu T, Yamazaki R, Aisa Y, Nakazato T, Ikeda Y, et al. Varicella-zoster virus infection under administration of ganciclovir after allogeneic bone marrow transplantation. Scand J Infect Dis. 2006;38:227-8.

37. Wong RW, Jumper JM, McDonald HR, Johnson RN, Fu A, Lujan $\mathrm{BJ}$, et al. Emerging concepts in the management of acute retinal necrosis. Br J Ophthalmol. 2013;97:545-52.

38. Aslanides IM, De Souza S, Wong DT, Giavedoni LR, Altomare F, Detorakis ET, et al. Oral valacyclovir in the treatment of acute retinal necrosis syndrome. Retina. 2002;22:352-4.

39. Emerson GG, Smith JR, Wilson DJ, Rosenbaum JT, Flaxel CJ. Primary treatment of acute retinal necrosis with oral antiviral therapy. Ophthalmology. 2006;113:2259-61.

40. Chau Tran TH, Cassoux N, Bodaghi B, Lehoang P. Successful treatment with combination of systemic antiviral drugs and intravitreal ganciclovir injections in the management of severe necrotizing herpetic retinitis. Ocul Immunol Inflamm. 2003;11: $141-4$.

41. King J, Chung M, DiLoreto DA Jr. A 9-year-old girl with herpes simplex virus type 2 acute retinal necrosis treated with intravitreal foscarnet. Ocul Immunol Inflamm. 2007;15:395-8. 
42. Muthiah MN, Michaelides M, Child CS, Mitchell SM. Acute retinal necrosis: a national population-based study to assess the incidence, methods of diagnosis, treatment strategies and outcomes in the UK. Br J Ophthalmol. 2007;91:1452-5.

43. Luu KK, Scott IU, Chaudhry NA, Verm A, Davis JL. Intravitreal antiviral injections as adjunctive therapy in the management of immunocompetent patients with necrotizing herpetic retinopathy. Am J Ophthalmol. 2000;129:811-3.

44. Wong R, Pavesio CE, Laidlaw DA, Williamson TH, Graham EM, Stanford MR. Acute retinal necrosis: the effects of intravitreal foscarnet and virus type on outcome. Ophthalmology. 2010;117: $556-60$. 